\title{
The Lecture is Not Dead: Combined Peer Assisted Flipped Class, an Alternative to Classical Lecture in Basic Medical Education
}

Noha Osama Shawky

Helwan Faculty of Medicine

Mohamed Fath EL-Bab

Helwan Faculty of Medicine

Nermien Waly ( $\square$ nermienwaly@creighton.edu )

Creighton School of Medicine https://orcid.org/0000-0002-1722-3142

Research article

Keywords: peer assisted learning (PAL), flipped classroom (FC)

Posted Date: January 19th, 2021

DOl: https://doi.org/10.21203/rs.3.rs-147715/v1

License: (c) (i) This work is licensed under a Creative Commons Attribution 4.0 International License.

Read Full License 


\section{Abstract}

Student engagement at lectures is declining especially for basic sciences. Lecture is main method of physiology teaching. It has been increasingly challenging to employ new educational methodologies in teaching physiology for several economical and technical reasons. Our objective was to enhance lecture attendance and increasing student engagement in physiology lectures. Combined peer assisted learning (PAL) and flipped classroom (FC) strategies (PAFC) was employed in the teaching of neurophysiology course for second year medical students. Course Material and reading assignments were provided ahead of class on instructor and departmental websites. Twenty Students participated in lectures preparation and presentation under instructor's supervision. Class members participation was conducted via pre-class reading assignments, in class discussions and instructor guided questions. Method evaluation was conducted using both course surveys, quizzes, end of course evaluations and lecture attendance.

lecture attendance showed about $30 \%$ increase compared to anatomy class conducted in classical lecture format. Course surveys revealed a $77 \%$ of students were satisfied with the new methodology while $23 \%$ preferred the traditional method. All PAFC participants expressed their positive feedback when interviewed after the course had ended and their comments was documented. End of course evaluations showed that class results were Comparable to anatomy course taught in traditional method (same class and conducted at the same time).

In conclusion, PAFC can be beneficial in teaching basic science courses for medical students. It can enhance lecture attendance and student satisfaction. Also, it can provide an affordable alternative method to improve medical education in institutes with limited resources.

\section{Introduction}

Although lectures remain the main method of large group teaching, medical students all over the world are abandoning lecture rooms $(1,2)$. Despite great benefits of lectures recently it has been a challenge to continue teaching medicine in the classical format lecture especially for basic science courses.

Teaching physiology has been generally conducted in a classical instructor centered methodology. It has been increasingly challenging to employ new educational methodologies in its teaching in Egyptian Schools of Medicine for several economical and technical reasons. On the other hand student attendance rates are declining (literature supported personal observation) (3) and it is hard to convince students to attend lectures. A major challenge is that innovative teaching methods are costly (in terms of equipment or even training personnel) and usually applicable on small number of students. That is why there is a need for applicable alternative methods that can overcome these challenges.

The flipped classroom approach (FC) is becoming very popular among modern learners and educators (4). FC inverts the traditional lecture model by presenting the course content outside of classroom ahead of the traditional lecture time and by replacing the lectures with active forms of learning in the classroom (5). Some medical schools e.g. Harvard Medical School have changed their curriculum to be presented in 
FC format both to enhance independent learning and to boost student attendance, while other schools have employed FC in only some courses $(6,7)$

Peer assisted learning (PAL) on the other hand is widely adopted in medical education to enhance student learning (8). Both methods are related to humanistic theories category that promotes self-directed learning and is learner-centered. These approaches are more suitable for medical and professional programs (9). Furthermore, recent medical education reforms nationally and internationally require the graduate to have teaching skills $(10,11)$.

The objective of this study was to enhance lecture effectiveness and improve attendance as well as increase student satisfaction of lecture as a learning tool. combined FC and PAL strategies (PAFC) was employed in teaching a neurophysiology course for second year medical students at Helwan school of medicine, Egypt. This PAFC model is a potential alternative for classical lecture in our settings and others.

\section{Methods}

All procedures were approved by the curriculum management committee and the institutional review board (IRB) according to Helwan School of medicine bylaws. Students signed a consent form of participation.

\section{- Overview:}

Combined peer assisted learning (PAL) and flipped classroom (FC) strategies was used in the teaching of an undergraduate neurophysiology course for second year medical students. PAFC strategy was used to deliver all lectures in this course as follows:

- Course Material and reading assignments were provided ahead of class (2 months) on instructor and departmental websites. Prior to course, it was announced to the whole class that pre-class reading assignments is essential, as during class students are required to participate in discussion.

- Twenty Students volunteered to participate in lectures preparation and presentation under instructor's supervision. Presenting students are announced as class tutors and prompted to form mini teaching groups to help their colleagues throughout the class. This activity is reported by each presenting student and recorded in their portfolio.

- Lecture preparation included preparing the power point presentations as well as rehearsal of the lecture. Topics were presented similar to original didactic syllabus. Student presenters constantly communicated with instructor via office hours or electronically for follow up or any questions regarding the material.

- Teaching session (lecture outline): The lecture typically starts with the student(s) presentation of class material. While the student is presenting, as rehearsed, the instructor step in to explain key information or ask questions to the whole class. Most (30-40\%) of the lecture time is consumed by 
active discussion. Students are prompted to ask questions themselves and answer questions if they can. Homework is given as well to encourage the students to continue reading as well.

\section{- PAFC evaluation Tools:}

This method was evaluated via both course surveys, quizzes and end of course evaluations as follows:

\section{Course survey}

An instructor-generated anonymous survey was administered manually to the students a few weeks before the end of the semester during the flipped classroom module to gather feedback about different aspects of the course. In addition to ratings, comment fields were included for several survey questions.

\section{End-of-module course surveys}

Students completed end-of-module course surveys mandated by the School of Medicine.

3. knowledge based end of course student's examinations:

students end of course grades were compared to same group results on different course (anatomy) taught in classical lecture format.

4. Student attendance was in PAFC was compared to that in other class (respiratory physiology) taught by the same instructor (to eliminate personal factor).

5. Data was plotted and analyzed using Excelâ

\section{Results}

- Class attendance in the PAFC model was $80 \%$. Average class attendance in other lectures taught by same instructor in the classic format was $50.6 \%$ (figure 1).

- Course surveys revealed that $77 \%$ of students preferred the new methodology while $23 \%$ preferred the traditional method (table 1).

- All PAFC participants expressed their positive feedback when interviewed after the course had ended and comments was documented (figure 2). The majority of the comments stated that PAFC helped them "actively" learning the material and that in class discussions guided them through the process. Students commented that it was "easier" to listen to the material explanation from a peer as they probably explain in a way similar to their own. At the other end of the spectrum, some students stated that it was difficult to do the pre-class readings and that in class discussions distracted them from learning the material.

- There was no significant difference in end of course final exam results compared to respiratory physiology course taught by the same instructor (course taught in traditional method, same students and conducted at a later time). Average student scores were and $90.45 \%$ and $89.83 \%$ respectively (figure 3). 


\section{Discussion}

Peer assisted flipped classroom (PAFC) method is an applicable alternative to classical lectures in physiology course as well as other basic sciences courses. This method has great beneficial impact on medical education.

Lecture is one of the oldest teaching formats that has survived overtime $(1,2)$. There have been several criticisms to the classic lecture format in education generally and specifically in medical education (12, 13). One of the major criticisms to lectures is lower retention rate due long duration and passive role of learners $(14,15)$. Also, student attendance of lectures is often not obligatory so that lectures may become obsolete (3).

Moving towards student centered, problem based, community oriented systematic approach (SPICES model) of education with special emphasis on student centered education is a major focus in Egyptian medical education national reform (16). We also have to consider how medical students learn, as adults, when preparing medical program/courses with respect to theories involved in adult learning $(9,17)$. We must also find an applicable alternative to large group teaching that matches our resources and logistics especially for basic sciences as physiology.

FC is appealing to both instructors and students $(12,18,19)$. On the other hand, although widely accepted, there is a limited data on the value of PAL in medical education (20). FC application alone can be challenging in our settings due to logistic constraints. Also, PAL has its merits, but it has to be used wisely to avoid its setbacks. Combining both in PAFC model proposed here was useful and doable in our settings.

Employing PAFC to my class and observing its results not only improved the class teaching but also brought the class students closer to me and to each other contrary to the situation in classical lecture (19, 21). The time spent on preparing and reviewing the material to be delivered in class was very energetic. This method definitely overcame student isolation from instructor and peer reported regarding traditional lecture (22). The student feedback results indeed showed that this method is widely acceptable by our students and enhanced deep learning and engagement (21). It also showed that they are enthusiastic about it and willing to apply it in other courses as well. Another great benefit of using PAFC was enhancement of class attendance. There may be several reasons for such a result and it is not surprising that one of them is rather social than educational. Students perceived the lecture as a scientific social event that they invite peers to attend. Lecture attendance is a growing concern in medical education, it is generally observed that students are deserting lecture halls $(3,23)$. Although one study showed that medical students still preferred human delivered classes, this result was based on the response of third of the target population (24).

Another institutional motivation to employ PAFC and incorporate it within its curricula's teaching strategies is that it complies with recent medical education reforms nationally and internationally requires the graduate to have teaching skills $(10,11)$. It also reduces physical teaching load of the instructor 
(although it may require longer time to prepare the session than regular lecture). This may be a good alternative especially in schools where there is a shortage of medical educators.

Although end of course evaluations showed that class results were comparable to course taught in traditional method it was more enjoyable conducting the course this way. This emotion was obvious in a video that the student made about the class and posted on social media (25).

\section{Conclusion}

In conclusion, combining PAFC in teaching physiology is an applicable alternative to classical lecture. This combination can overcome technical limitations of using each method alone. It can enhance lecture attendance and student satisfaction. Also, it can provide an affordable alternative method to improve medical education in institutes with limited resources.

\section{Declarations}

\section{Acknowledgment:}

The authors are grateful for Prof. Thomas Pisarri, Creighton School of Medicine for his invaluable editorial assistance. The authors would also like to thank all staff members (TA and administration staff) at the department of physiology of Helwan school of medicine for their help with courses administration and paperwork.

Funding: this research received no funding.

Conflict of Interest: authors declare no conflict of interest.

Availability of data and material non applicable

Code availability non applicable

Authors' contribution: Nermien Waly designed the research and drafted the manuscript. Noha Osama Shawky performed data analysis. All authors contributed equally to research execution, as well as reading and approval of final manuscript.

Ethics approval: All procedures were approved by the curriculum management committee as well is the institutional research ethics committee in accordance to Helwan School of medicine bylaws.

Consent to participate students signed a consent form to participate in this research.

Consent for publication all authors read and approved final manuscript and consent to publish.

Informed consent: Students signed a consent form of participation. 


\section{References}

1. Cooper AZ, Richards JB. Lectures for Adult Learners: Breaking Old Habits in Graduate Medical Education. Am J Med. 2017;130(3):376-81.

2. Hurst JW. The overlecturing and underteaching of clinical medicine. Arch Intern Med. 2004;164(15):1605-8.

3. Kanter SL. To be there or not to be there: is attendance really the question? Acad Med. 2012;87(6):679.

4. King A, Boysen-Osborn M, Cooney R, Mitzman J, Misra A, Williams J, et al. Curated Collection for Educators: Five Key Papers about the Flipped Classroom Methodology. Cureus. 2017;9(10):e1801.

5. White PJ, Naidu S, Yuriev E, Short JL, McLaughlin JE, Larson IC. Student Engagement with a Flipped Classroom Teaching Design Affects Pharmacology Examination Performance in a Manner Dependent on Question Type. Am J Pharm Educ. 2017;81(9):5931.

6. Dienstag JL. Evolution of the New Pathway curriculum at Harvard Medical School: the new integrated curriculum. Perspect Biol Med. 2011;54(1):36-54.

7. Chen F, Lui AM, Martinelli SM. A systematic review of the effectiveness of flipped classrooms in medical education. Med Educ. 2017;51(6):585-97.

8. Habib SH, Malik MO, Fatima S, Shah I. Evaluation Of Peer Assisted Learning In Evidence Based Medicine Course: A Pilot Study At University Of Glasgow. J Ayub Med Coll Abbottabad. 2017;29(4):662-6.

9. Durning SJ, Artino AR. Situativity theory: a perspective on how participants and the environment can interact: AMEE Guide no. 52. Med Teach. 2011;33(3):188-99.

10. Council. GM. Tomorrow's Doctors: Outcomes and Stan- dards for Undergraduate Medical Education (online). 2016 [Available from: http://www.gmcuk.org/Tomorrow_s_Doctors_1214.pdf_48905759.pdf [9 June 2016].

11. (NAQAA) ENAfQAaA. National Academic Reference Standard for Medical Graduate (NARS) 2016 [2017:[Available from: http://naqaae.eg/wp-content/uploads/2014/10/Medicine.pdf.

12. Prober CG, Heath C. Lecture halls without lectures--a proposal for medical education. N Engl J Med. 2012;366(18):1657-9.

13. White G. Interactive lecturing. Clin Teach. 2011;8(4):230-5.

14. Masters K. Edgar Dale's Pyramid of Learning in medical education: a literature review. Med Teach. 2013;35(11):e1584-93.

15. Sawatsky AP, Zickmund SL, Berlacher K, Lesky D, Granieri R. Understanding resident learning preferences within an internal medicine noon conference lecture series: a qualitative study. J Grad Med Educ. 2014;6(1):32-8.

16. Harden RM, Sowden S, Dunn WR. Educational strategies in curriculum development: the SPICES model. Med Educ. 1984;18(4):284-97. 
17. Taylor DC, Hamdy H. Adult learning theories: implications for learning and teaching in medical education: AMEE Guide No. 83. Med Teach. 2013;35(11):e1561-72.

18. Mehta NB, Hull AL, Young JB, Stoller JK. Just imagine: new paradigms for medical education. Acad Med. 2013;88(10):1418-23.

19. Ezzat A, Dynes K, Parson SH. Evolving student-faculty partnerships in medical education through peer-assisted learning. Med Educ. 2016;50(5):568.

20. Sammaraiee Y, Mistry RD, Lim J, Wittner L, Deepak S, Lim G. Peer-assisted learning: filling the gaps in basic science education for preclinical medical students. Adv Physiol Educ. 2016;40(3):297-303.

21. Micari M, Streitwieser, B. \& Light, G. . Undergraduates Leading Undergraduates: Peer Facilitation in a Science Workshop Program. Innov High Educ. 2006;4(30):269.

22. Dewey J. The need for a philosophy of education. . In: R. D. Archambault (Ed.), editor. John Dewey on education: Selected writings Chicago, IL: University ofChicago Press.; 1964. p. 3-14.

23. Kauffman CA, Derazin M, Asmar A, Kibble JD. Relationship between classroom attendance and examination performance in a second-year medical pathophysiology class. Adv Physiol Educ. 2018;42(4):593-8.

24. Lucinda Wynter* AB, Eszter Kalman, Jack Edward Heron and Jane Bleasel. Medical students: what educational resources are they using? BMC Medical Education. 2019:19-36.

25. Waly N. Flipped Class Room Documentary in Helwan University Medical School. You Tube2017 [Available from: https://www.youtube.com/watch?v=4owv5-PwszY.

\section{Tables}

Due to technical limitations, table 1 is only available as a download in the Supplemental Files section.

\section{Figures}




\section{Attendance rates in PAFC class model and classical lecture}

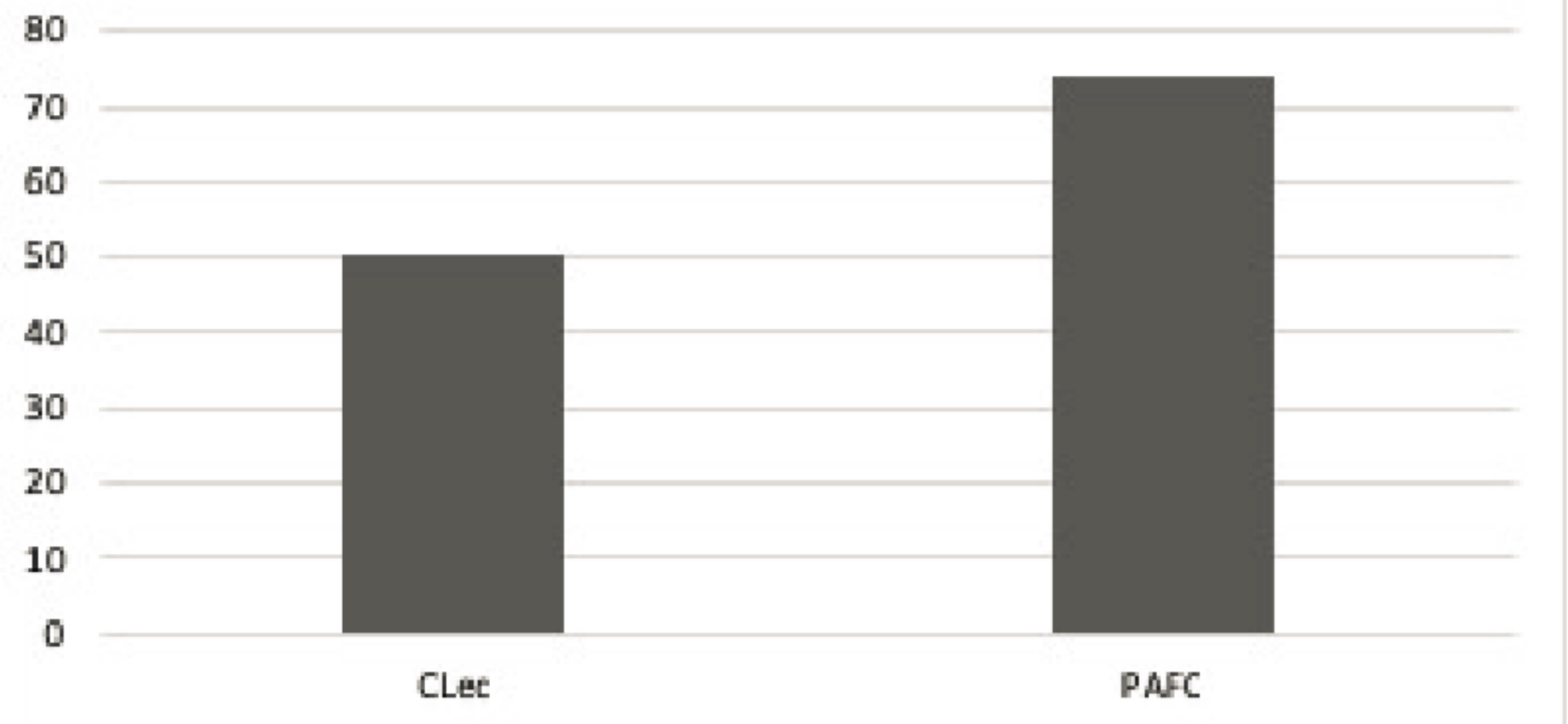

\section{Figure 1}

Attendance in Peer Assisted Flipped Classroom (PAFC) versus Classical Lecture (CLec): average class attendance in PAFC in neurophysiology course for second year medical students was $80 \%$ while that of CLec for respiratory physiology was $50.6 \%$. Both classes were taught by same instructor and same year. Total number of students enrolled in both classes was 159 students. 


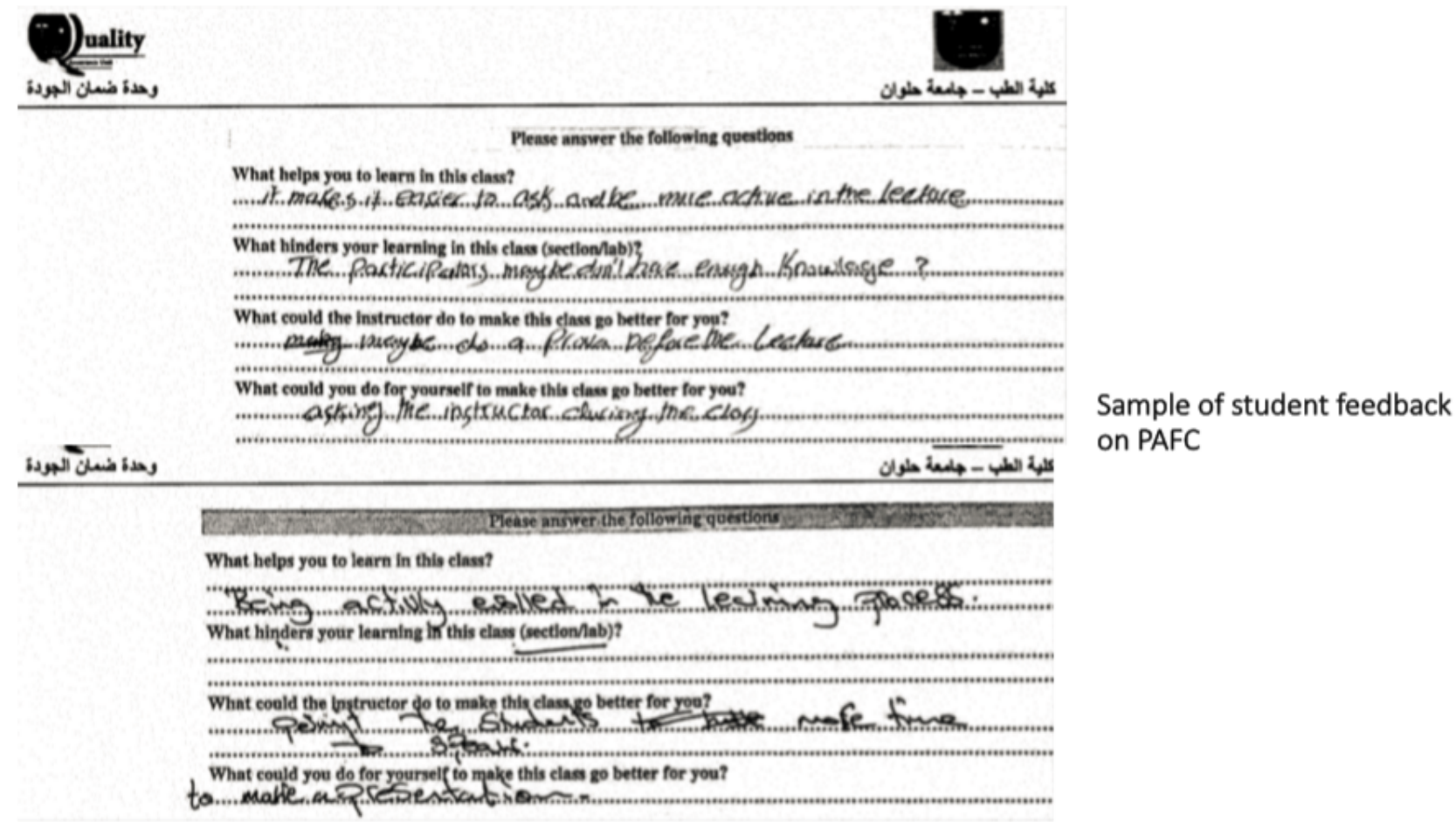

Figure 2

Sample of student written anonymous feedback regarding PAFC method.

\section{Comparison of student final exam scores in PAFC and classic lecture (CLec) models}

$100 \%$

$50 \%$

$0 \%$

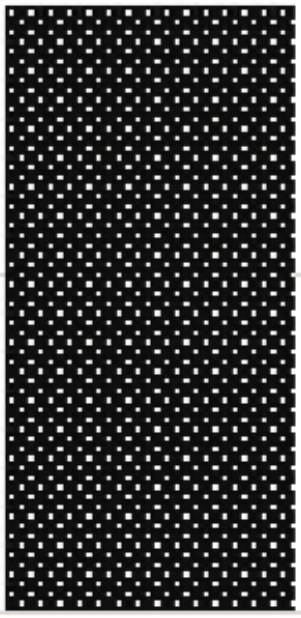

Clè

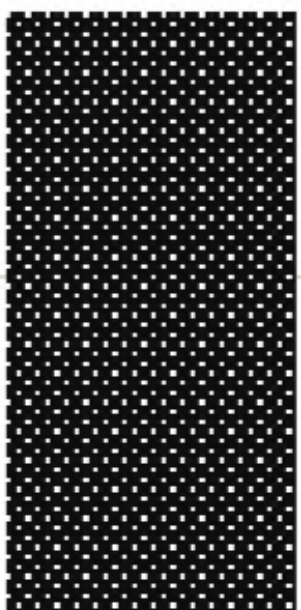

PAFC

Figure 3 
A comparison between student final student course results (grades) in both neurophysiology course conducted using PAFC and respiratory physiology course conducted in classical lecturing format (CLec). Average student scores were $89.83 \%$ and $90.45 \%$. Respectively.

\section{Supplementary Files}

This is a list of supplementary files associated with this preprint. Click to download.

- Table1.pdf 